\title{
Correções zpva para as segundas hiperpolarizabilidades de clusters $(\mathrm{MgO})_{\mathrm{n}}$
}

\author{
Luan S. Feitoza ${ }^{1,2(\mathrm{PG})^{*}}$, Marcos A. Castro ${ }^{1(\mathrm{PQ})}$, Salviano Leão ${ }^{1(\mathrm{PQ})}$, Tertius L. Fonseca ${ }^{1(\mathrm{PQ})}$ \\ *luan.feitoza@ifb.edu.br \\ ${ }^{1}$ Instituto de Física, Universidade Federal de Goiás, Campus Samambaia, 74690-900, Goiânia, Goiás \\ ${ }^{2}$ Instituto Federal de Brasília - IFB, Campus Planaltina, 73380-900, Brasília, Distrito Federal \\ Palavras-chave: Correções vibracionais, clusters, segunda hiperpolarizabilidade, zpva.
}

\section{Introdução}

Clusters têm atraído muito interesse em pesquisas teóricas e experimentais por apresentarem propriedades distintas das observadas em moléculas e sólidos. Dentre as características peculiares desses aglomerados está a mudança de suas propriedades com parâmetros como o tipo de ligação e o tamanho do sistema. Uma das propriedades físicas que possuem dependência com o tamanho do cluster são as (hiper)polarizabilidades. Esses tensores são objeto de interesse no estudo de sistemas atômicos e moleculares desde os primórdios da mecânica quântica, pois além de se relacionarem a fenômenos óticos não lineares relevantes, têm aplicações elementares em fotônica, chaves elétricas e espalhamento. Embora existam resultados para as (hiper)polarizabilidades eletrônicas de clusters [1], há uma escassez na literatura de artigos que considerem as correções vibracionais para essas propriedades. A inclusão das contribuições vibracionais para a correta determinação das (hiper)polarizabilidades é um consenso no estudo de muitas moléculas [2, 3]; os resultados que obtivemos em dois trabalhos anteriores para os clusters de fosforeto de alumínio [4] e oxido de magnésio [5] indicam que essas correções também são importantes para clusters atômicos. As correções vibracionais podem ser vistas como a soma de duas parcelas: a correção da média vibracional de ponto zero (zero point vibrational avarage - zpva) e a correção vibracional pura (pure vibrational - $p v$ ). Neste novo estudo, decidimos computar as correções zpva para clusters de óxido de magnésio - $(\mathrm{MgO})_{\mathrm{n}}$, uma vez que, até onde sabemos, não há trabalhos na literatura tratando desse tema para o caso especifico de clusters. Pretendemos investigar como essa correção se comporta em função do tamanho do cluster e se suas contribuições são significativas. As geometrias otimizadas e frequências vibracionais harmônicas foram computados por meio do programa Gausssian 09; os cálculos das segundas hiperpolarizabilidades eletrônicas foram feitos utilizando o programa Dalton 2013. Todos os cálculos foram efetuados com o conjunto de funções base aug-cc-pVDZ por meio da Teoria do Funcional de Densidade (DFT) através do funcional CAM-B3LYP.

\section{Metodologia}

Na literatura [6], o valor total de uma propriedade $p$ é comumente escrito na forma

$$
p^{t o t}=p^{e l}\left(R_{e q}\right)+p^{z p v a}+p^{p v}
$$

onde $p^{e l}\left(R_{e q}\right)$ é a contribuição eletrônica da propriedade calculada na geometria de equilíbrio, $p^{z p v a}$ é a correção da média vibracional de ponto zero e $p^{p v}$ é a correção vibracional pura. Bishop e Kirtman deduziram expressões para o cálculo das correções vibracionais através de uma metodologia chamada Método da Perturbação Teórica (BKPT) [7]. As expressões foram escritas em termos da notação $[p]^{\mathrm{m}, \mathrm{n}}$, onde $m$ representa a ordem de anarmonicidade elétrica e $n$ a ordem de anarmonicidade mecânica. As correções zpva para a segunda hiperpolarizabilidade $(\gamma)$ via BKPT podem ser escritas como a soma de duas parcelas: $\gamma^{z p v a}=[\gamma]^{1,0}+[\gamma]^{0,1}$, sendo que 


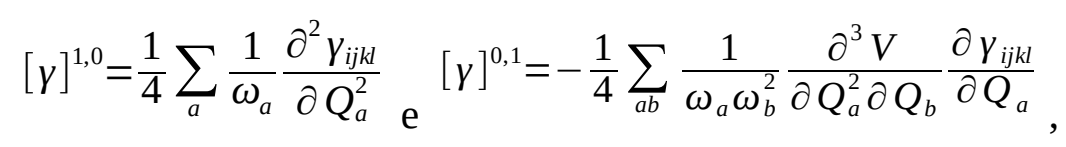

onde $\mathrm{Q}_{\mathrm{a}}$ e $\omega_{\mathrm{a}}$ são a coordenada normal e a frequência angular correspondentes ao modo normal de vibração $a$, respectivamente.

\section{Resultados}

Os sistemas estudados neste trabalho são os clusters $(\mathrm{MgO})_{\mathrm{n}}$, com $\mathrm{n}=2$ - 9. Para os sistemas com $n=2-5$, os termos $[\gamma]^{1,0}$ das correções zpva foram 557, 348, 3185, 4232 u.a, respectivamente; enquanto que os resultados para o termo $[\gamma]^{0,1}$ são $268,351,752$, 301 u.a., respectivamente, correspondendo entre 1 e 5\% das contribuições eletrônicas. Também determinamos os valores do termo $[\mathrm{\gamma}]^{0,1}$ para os clusters $(\mathrm{MgO})_{6}$ e $(\mathrm{MgO})_{9}$. apresentando os valores 904 e 1440 u.a., respectivamente.

\section{Discussão}

As correções zpva para clusters, assim como ocorrem em moléculas, forneceram contribuições percentuais menores do que às correções $p v$ e demostraram ser pequenas em comparação com os respectivos resultados eletrônicos. Percebemos também que os sistemas maiores apresentaram correções percentuais superiores.

\section{Conclusões}

As correções zpva para clusters atômicos ainda não haviam sido determinadas. Nosso trabalho mostra que essas correções são percentualmente pequenas. Clusters com mais átomos apresentam correções percentuais maiores em relação às contribuição eletrônicas.

\section{Agradecimentos}

Este trabalho foi parcialmente financiado pelo CNPq, CAPES e FAPEG. Agradecemos aos recursos do laboratório de computação LCC-IFUFG e ao Instituto Federal de Brasília - IFB pelo apoio ao desenvolvimento da pesquisa.

\section{Referências}

[1] P. KARAMANIS, J. LESZCZYNSKI. The Journal of Chemical Physics, v. 128, n. 15, p. 154323, apr 2008.

[2] D. M. BISHOP, D. W. De KEE. The Journal of Chemical Physics, v. 104, n. 24, p. 9876-9887, jun 1996.

[3] E. S. NAVES,; M. A. CASTRO, T. L. FONSECA. The Journal of Chemical Physics, v. 134, n. 5, p. 054315, feb 2011.

[4] L. FEITOZA, O. SILVEIRA, M. A. CASTRO, S. A. LEÃO, T. L. FONSECA. The Journal of Chemical Physics, v. 143, n. 22, p. 224302, dec 2015.

[5] L. FEITOZA, M. A. CASTRO, S. A. LEÃO, T. L. FONSECA. The Journal of Chemical Physics, v. 146, n. 14, p. 144309, apr 2017.

[6] BISHOP, D. M. Aspects of Non-Linear-Optical Calculations. In: . [s.n.], 1994.

[7] BISHOP, D. M.; LUIS, J. M.; KIRTMAN, B.The Journal of Chemical Physics, v. 108, n. 24, p. 10013-10017, jun 1998. 